\title{
PREVALÊNCIA DA INFECÇÃO PELO VÍRUS DA ARTRITE ENCEFALITE CAPRINA NO ESTADO DO CEARÁ, BRASIL
}

\author{
PREVALENCE OF CAPRINE ARTHRITIS ENCEPHALITIS VIRUS INFECTION \\ IN THE STATE OF CEARÁ, BRAZIL
}

\author{
Raymundo Rizaldo Pinheiro ${ }^{1}$ Aurora Maria Guimarães Gouveia ${ }^{2}$ Francisco Selmo Fernandes Alves ${ }^{3}$
}

RESUMO

A elevação do risco de contaminação pelo vírus da artriteencefalite caprina (CAEV) em rebanhos caprinos nativos e sem raça definida (SRD) tem sido verificada paralelamente à introdução de caprinos de raças exóticas no Brasil, o que motivou a realização deste levantamento epidemiológico no Estado do Ceará. Para o diagnóstico da infecção pelo CAEV, utilizou-se a microtécnica de imunodifusão em gel de ágar. Foram pesquisadas 4019 amostras de soro caprino em 30 municípios do Ceará. A prevalência da infecção pelo CAEV verificada foi de $1 \%$ (40/4019 animais), sendo a maior prevalência $(11,1 \%)$ na região metropolitana de Fortaleza. Analisando a distribuição de animais soropositivos nos municípios pesquisados, constatou-se que um terço dos municípios (10/30) apresentaram pelo menos um animal soropositivo. Verificou-se maior prevalência $(p<5 \%)$ nos caprinos mais velhos quando comparados com os jovens. A análise por sexo e composição do rebanho mostrou que os machos estavam estatisticamente mais afetados $(p<5 \%)$. Conside rando-se o grau de sangue, 5,02\% de raças puras e 0,12\% de animais mestiços apresentavam anticorpos contra CAEV. Dentre os soropositivos, a raça Parda Alpina foi estatisticamente mais afetada $(p<5 \%)$. Com base nos resultados, pode-se verificar que o lentivírus de pequenos ruminantes já se encontra disseminado nas várias regiões do Ceará e que, provavelmente, os reprodutores sejam a principal fonte de transmissão viral entre os rebanhos nativos/SRD

Palavras-chave: caprino, lentivírus, CAEV, prevalência, Ceará.

\section{SUMMARY}

This epidemiological study in the State of Ceará, Brazil was motivated by the risk of infection with caprine arthritis encephalitis virus (CAEV) through introduction of exotic caprines. For diagnosis of CAEV infection the agar gel imunodifusion microtechnic was used. 4019 goat serum samples were collected in 30 counties. The prevalence of CAEV infection was 1\% (40/4019 animals). The highest prevalence (11.1\%) was found in the metropolitan area of Fortaleza, the area with highest goat milk production. The analysis of the distribution of seropositive animals in the studied counties showed that $33 \%$ (10/30) had at least one positive animal. The highest prevalence was found $(p<0.05)$ in older animals. The males were more affected $(p<0.05)$. The pure breeds presented $5.02 \%$ of animals with antibodies against the CAEV and the half-breeds $0,12 \%$. The Alpine breed was the more affected $(p<0.05)$ among all breeds studied. It was verified that the small ruminant lentivirus is already disseminated in several areas of the Stete of Ceara and that the males are probably the main source of transmission to the native/SRD flocks.

Key words: goat, caprine lentivirus, CAEV, prevalence, Ceara state.

\section{INTRODUÇÃO}

A Artrite Encefalite Caprina (CAE), causada por lentivírus de pequenos ruminantes ("small ruminant lentiviruses" - SRLV), acarreta grandes perdas econômicas nos rebanhos caprinos, principalmente naqueles de produção leiteira, afetando animais de diferentes raças, idades e sexos (DAWSON, 1989). As perdas econômicas se caracterizam por morte de animais jovens, diminuição da produção láctea e perda de peso dos adultos devido a dificuldades de locomoção. Perdas indiretas importantes decorrem da desvalorização dos rebanhos, reposição precoce de animais, despesas com medidas de controle e barreiras comerciais para produtos (matrizes, reprodutores e sêmen). No Brasil, sua

${ }^{1}$ Pesquisador da EMBRAPA-Caprinos, MSc., Escola de Veterinária, DMVP, Universidade Federal de Minas Gerais (UFMG), CP 567, 30160910, Belo Horizonte/MG. E-mail: aurora@ vet.ufmg.br. Autor para correspondência.

${ }^{2}$ Professor Adjunto PhD., Departamento de Medicina Veterinária Preventiva (DMVP), UFMG.

${ }^{3}$ Pesquisador da EMBRAPA-Caprinos. PhD. 
presença foi constatada inicialmente no Rio Grande do Sul (MOOJEN et al., 1986). No Ceará, o primeiro registro dessa infecção ocorreu em animais de raças leiteiras no município de Sobral (PINHEIRO et al., 1989). Em levantamento realizado em rebanhos leiteiros na região metropolitana de Fortaleza RMF (CE), verificou-se soroprevalência de 40,7\% de animais positivos para SRLV (MELO \& FRANKE, 1997).

O efetivo caprino do Ceará é de 795.690 cabeças (IBGE, 1999) composto basicamente por raças nativas da região (nativos) e animais sem raça definida (SRD). A produção de leite de cabra é explorada na região Nordeste de maneira semiintensiva, exceto nas propriedades rurais situadas próximo aos grandes centros urbanos, onde existe maior número de criatórios com sistema de criação intensivo (SILVA, 1996).

No Nordeste brasileiro, levando-se em conta a realidade sócio-econômica e o tipo de exploração zootécnica predominante, a presença de SRLV nos animais leiteiros representa grande risco de disseminação do agente para os rebanhos nativo e SRD. A pouca informação sobre CAE tem limitado a implantação e avaliação de medidas profiláticas, sendo o levantamento epidemiológico da infecção pelo CAEV o primeiro passo para seu controle. Até o presente, todos os trabalhos realizados no Brasil foram em rebanhos de caprinos leiteiros, onde foi comprovada a alta prevalência da infecção. A suspeita de que a introdução de animais, principalmente reprodutores puros e/ou mestiços, sem um devido controle, tenha elevado o risco de contaminação dos rebanhos nativos/SRD, motivou a realização deste levantamento epidemiológico, com ênfase nos rebanhos que apresentam algum grau de melhoramento e nos nativos/SRD.

\section{MATERIAL E MÉTODOS}

A coleta das amostras de soro foi realizada nas várias regiões criadoras de caprinos de raças leiteiras e nativos/SRD do Ceará no período de fevereiro a julho de 1997. Como universo amostral foram selecionadas 130 propriedades através de amostragem não probabilística. $\mathrm{O}$ rebanho foi considerado leiteiro quando os animais eram ordenhados regularmente e o leite utilizado para consumo próprio ou comercializado. No caso dos animais nativos/SRD, foram escolhidas propriedades nos municípios de maior representatividade para o Estado ou para a microrregião. Foram incluídos somente animais com idade superior a seis meses.

O número mínimo de amostras a serem testadas (n) foi calculado de acordo com
ASTUDILLO (1979), considerando uma prevalência esperada de $2 \%$. Foram amostrados rebanhos caprinos de vários tipos de sistema de criação, assumindo um erro amostral de $22 \%$ e um grau de confiança de $95 \%(\mathrm{z}=1,96)$. Assim, foi estabelecido um $\mathrm{n}=3963$, correspondendo a cerca de 30 animais por fazenda, estratificados segundo a composição aproximada dos rebanhos em: $65 \%$ de matrizes, $25 \%$ de jovens (entre 6 a 12 meses) e todos os reprodutores adultos.

Para detecção de anticorpos contra SRLV foi utilizada a microtécnica de imunodifusão em gel de ágar (MIDGA) descrita por GOUVEIA (1994), utilizando antígeno comercial ${ }^{\mathrm{a}}$.

Com base nos resultados sorológicos foram calculadas a prevalência e as freqüências nos estratos, para presença de infecção pelo $\mathrm{CAEV}$, objetivando-se verificar a existência de diferenças significativas entre os resultados obtidos para os atributos raça, sexo, faixa etária e tipo racial, utilizando-se o teste Qui-quadrado $\left(\chi^{2}\right)$ com o auxílio do programa EPI-INFO (DEAN et al. 1992).

\section{RESULTADOS E DISCUSSÃO}

Foram estudadas 4019 amostras de soro caprino de 130 criatórios localizados em 30 municípios do Ceará. A prevalência da infecção do CAEV foi de 1\% (40/4019 animais) considerando todos os tipos raciais de caprinos testados. Entretanto, a prevalência em rebanhos leiteiros foi de 4,6\% (37/810), enquanto que em Pernambuco foi de 17,6\% (70/397) (SARAIVA NETO, 1993), e 29,8\% (615/2065) no Estado de São Paulo (FERNANDES, 1997). ASSIS (1993), em estudo sorológico de caprinos provenientes de criatórios de Minas Gerais, Rio de Janeiro, Bahia e Ceará, verificou presença de anticorpos para SRLV em 33,3\% (205/615), 29,7\% (30/101), 27,5\% $(211 / 768)$ e $12,8 \%(15 / 117)$ em Minas Gerais, Rio de Janeiro, Ceará e Bahia, respectivamente. No Rio de Janeiro, constatou-se prevalência de 22,9\% (22/97) em amostras de soro coletadas no período entre 1982 e 1988 e de $20 \%$ (29/145) em caprinos, coletadas no período entre 1993 e 1994 (CUNHA \& NASCIMENTO, 1995).

Com relação à prevalência por região do Ceará, constatou-se maior prevalência da infecção $(11,1 \%)$ na RMF, justamente a maior bacia leiteira caprina. Essa prevalência representou 57,5\% dos animais soropositivos encontrados, sendo, portanto, a região com o maior número de animais infectados pelo CAEV. Esse achado é confirmado por MELO \& FRANKE (1997) que observaram prevalência de 40,7\% nos rebanhos leiteiros da RMF. As regiões norte e centro do Estado são outras bacias leiteiras caprinas onde foram encontrados $1,0 \%$ e $0,3 \%$ de

Ciência Rural, v. 31, n. 3, 2001. 
soropositividade, respectivamente. Na região dos Inhamuns, caracterizada quase exclusivamente por criações extensivas e sem introdução de animais de raças leiteiras, como também na região Sul do Estado, não foram observados caprinos reagentes (Tabela 1). O número reduzido de fazendas e animais pesquisados na RMF deveu-se ao fato da prevalência do CAEV, esperada nessa região, ser alta em função da concentração de rebanhos leiteiros, comprovada por MELO \& FRANKE (1997), o que não ocorreu nas outras regiões.

Analisando a distribuição de caprinos soropositivos nos municípios, pelo menos um rebanho com caprinos soropositivos (Figura 1) e que o município de Fortaleza deteve quase a metade dos animais soropositivos, seguido pelo município de Sobral, um grande município produtor de leite caprino do Ceará. Verificando a percentagem de municípios com animais positivos em relação à totalidade de municípios pesquisados na região, observou-se que na RMF $100 \%$ dos municípios $(2 / 2)$ tinham caprinos soropositivos, a região norte $62,5 \%(5 / 8)$, região Central 42,9\% (3/7), Inhamuns 0\% (0/3) e Sul 0\% $(0 / 9)$.

De acordo com a origem dos caprinos, os animais soropositivos eram procedentes, na sua maioria, da RMF (55\%), entretanto a introdução de caprinos procedentes de outros estados $(22,5 \%)$ ou países $(10 \%)$ contribuíram para disseminação da infecção no Ceará (Tabela 2).

$\mathrm{Na}$ distribuição do CAEV por propriedade, constatou-se que 9,2\% (12/130) das fazendas pesquisadas apresentavam pelo menos um animal positivo no rebanho. Na RMF, $66,7 \%$ das fazendas apresentavam caprinos soropositivos para CAE, seguida por $12,8 \%$ e $7,9 \%$ nas regiões Norte e Central, respectivamente. MELO \& FRANKE (1997), estudando a RMF, verificaram que $75 \%$ das propriedades leiteiras apresentavam caprinos soropositivos,

Tabela 1 - Diagnóstico sorológico da infecção por lentivírus de pequenos ruminantes por microimunodifusão em gel de ágar* em caprinos nas diversas regiões do Estado do Ceará, 1999.

\begin{tabular}{|c|c|c|c|c|c|c|}
\hline \multirow[t]{2}{*}{ Região } & \multirow[t]{2}{*}{ Número de Fazendas } & \multicolumn{2}{|c|}{ Reagente } & \multicolumn{2}{|c|}{ Não Reagente } & \multirow[t]{2}{*}{ Total } \\
\hline & & Número & $\%$ & Número & $\%$ & \\
\hline RMF*** & 5 & 23 & 11,1 & 185 & 88,9 & 208 \\
\hline Norte & 39 & 14 & 1,0 & 1422 & 99,0 & 1436 \\
\hline Central & 38 & 3 & 0,3 & 1018 & 99,7 & 1021 \\
\hline Inhamuns & 26 & 0 & 0,0 & 735 & 100,0 & 735 \\
\hline Sul & 22 & 0 & 0,0 & 619 & 100,0 & 619 \\
\hline Total & 130 & 40 & 1,00 & 3979 & 99,0 & 4019 \\
\hline
\end{tabular}

\footnotetext{
* Kit - Veterinary Diagnostic Technology, Inc ${ }^{\circledR}$
}

** RMF - Região metropolitana de Fortaleza enquanto SARAIVA NETO (1993), em Pernambuco, verificou soropositividade para CAEV em $70 \%$ das propriedades. ASSIS (1993), pesquisando quatro propriedades leiteiras em Minas Gerais, duas na Bahia e três no Ceará, verificou que $100 \%$ apresentavam animais soropositivos.

Quanto à idade dos animais positivos, verificou-se maior prevalência $(\mathrm{p}<5 \%)$ nos caprinos mais velhos quando comparados com os jovens. SARAIVA NETO (1993) relata que animais mais velhos são geralmente de elevado padrão zootécnico, sendo portanto mantidos por mais tempo no rebanho do que os demais. Os caprinos acima de três anos de idade representaram 32,5\% dos animais soropositivos, seguidos de animais de dois a três anos de idade $(25 \%)$, de um a um ano e meio (20\%), de um ano e meio a dois anos (15\%) e de seis meses a um ano $(7,5 \%)$. Os dados encontrados no trabalho corroboram com FERNANDES (1997), SARAIVA NETO (1993) e CUTLIP et al. (1992) os quais verificaram, em São Paulo, Pernambuco e Estados Unidos, respectivamente, que a taxa de prevalência de animais reagentes aumenta com a faixa etária. DAWSON \& WILESMITH (1985) relataram maior percentual de soropositividade aos antígenos dos SRLV em caprinos com mais de cinco anos de idade. Entretanto, MELO \& FRANKE (1997), na RMF, verificaram que animais mais jovens apresentaram maior positividade com relação a animais mais velhos, em decorrência da transmissão por leite e/ou colostro. Segundo MCGUIRE (1987), por se tratar de uma enfermidade de evolução lenta e por proporcionar maior probabilidade de exposição dos animais ao vírus, é provável que ocorra uma taxa elevada de reagentes nos animais mais velhos.

A análise por sexo e composição do rebanho (reprodutores, matrizes e jovens) mostrou que tanto os machos como a categoria reprodutores estavam mais afetados $(\mathrm{p}<5 \%)$ que as fêmeas e matrizes e os jovens (seis a 12 meses de idade), respectivamente (Tabela 3). Esses dados se contrapõem aos de CRAWFORD \& ADAMS (1981), MELO \& FRANKE (1997) e FERNANDES (1997) os quais não verificaram diferença $(\mathrm{p}>5 \%)$ quanto ao sexo e de SARAIVA NETO (1993) o qual não verificou diferença com relação a sexo ou composição do rebanho. Segundo CRAWFORD \& ADAMS (1981), não existem fatores relacionados ao sexo que predisponham à infecção pelos SRLV. Entretanto, como este trabalho pesquisou um maior número de fazendas formadas por caprinos mestiços oriundos de melhoramento dos rebanhos nativo/SRD, onde são utilizados principalmente reprodutores puros leiteiros ou mesmo mestiços, o número de amostras de caprinos machos com

Ciência Rural, v. 31, n. 3, 2001. 


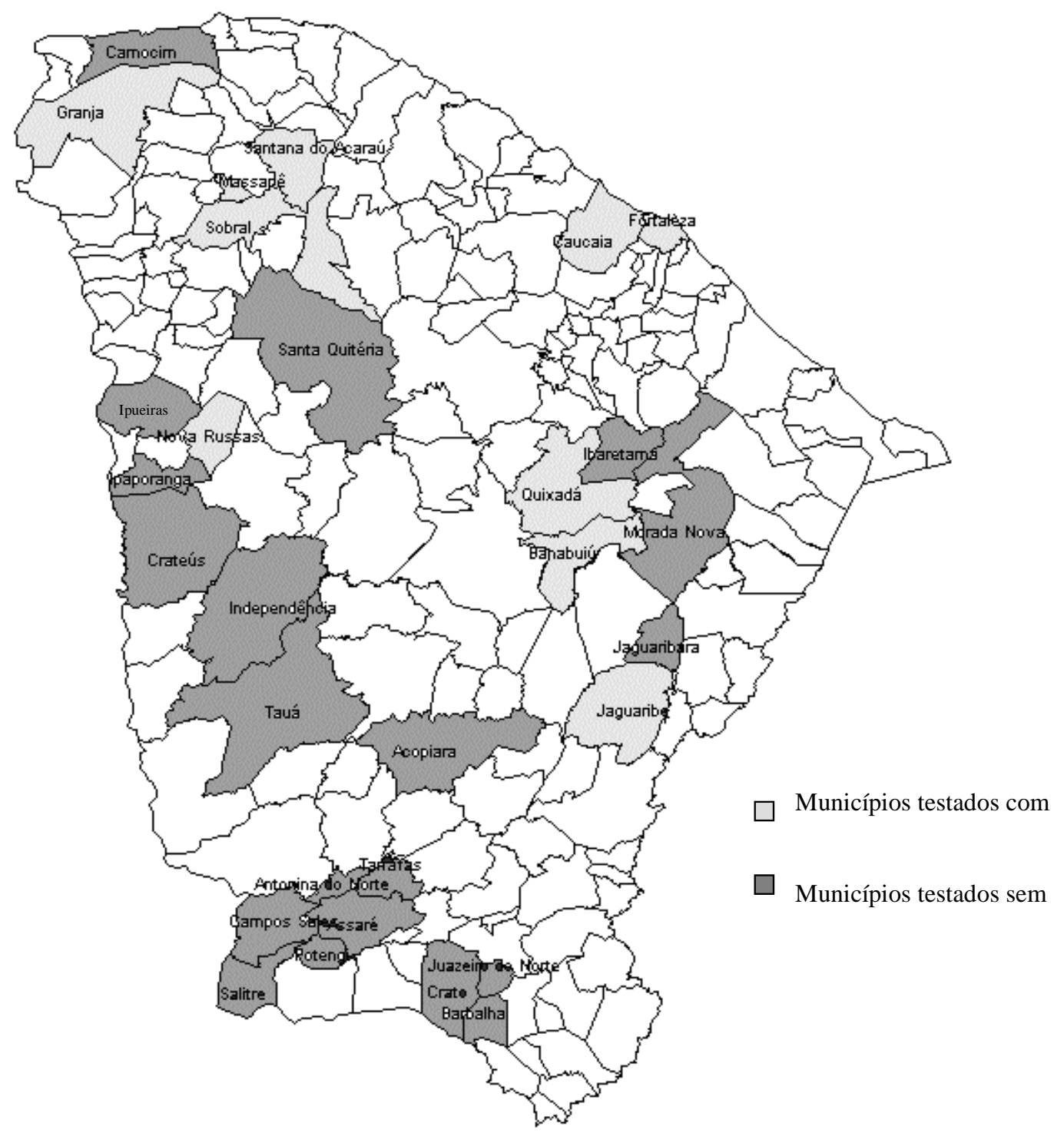

Figura 1- Municípios do Estado do Ceará onde foi realizada a pesquisa em caprinos para detecção de anticorpos contra CAEV.

infecção aumentou. Das 26 fêmeas positivas, somente uma encontrava-se numa fazenda com regime extensivo, enquanto que dos 14 reprodutores positivos quatro encontravam-se nessa categoria. Portanto, é provável que os reprodutores sejam a principal fonte de infecção desses rebanhos. Na tabela 3, pode-se verificar que nas raças puras leiteiras o percentual de reprodutores é praticamente o dobro que o percentual de fêmeas e jovens $(\mathrm{p}<5 \%)$.

Quando se levou em conta o grau de sangue dos animais, 4,6\% (37/810) de raças puras leitei- ras e $0,1 \%(3 / 2410)$ de caprinos mestiços apresentavam anticorpos contra SRLV, enquanto nenhum animal (0/869) nativo/SRD apresentou-se reagente (Tabela 3). Provavelmente, uma das causas da menor prevalência nos animais mestiços com relação aos animais puros esteja na formação dos rebanhos mestiços, nos quais comumente se introduz um reprodutor puro, o que tem restringido a transmissão vertical. As raças puras leiteiras representaram 92,5\% ( $<<0,5 \%)$ dos caprinos com SRLV. A raça Parda Alpina foi mais afetada $(\mathrm{p}<5 \%)(8 / 35)$ quando

Ciência Rural, v. 31, n. 3, 2001. 
Tabela 2 - Distribuição, segundo sua procedência, dos caprinos soropositivos para infecção pelo vírus da artrite encefalite caprina no Ceará, 1999.

\begin{tabular}{lrr}
\hline Origem do animal soropositivo & Quantidade & $\%$ \\
\hline & & \\
Região metropolitana de Fortaleza & 22 & 55,0 \\
Rio de Janeiro & 5 & 12,5 \\
Estados do Nordeste & 4 & 10,0 \\
Outros países & 4 & 10,0 \\
Região de Sobral & 3 & 7,5 \\
Cria da Fazenda & 2 & 5,0 \\
Total & 40 & 100,0 \\
& & \\
\hline
\end{tabular}

comparada com os outros tipos raciais estudados (Tabela 3). Convém salientar que a raça Anglo Nubiana foi a que apresentou o maior número de animais soropositivos, representando $55 \%$ dos mesmos. MELO \& FRANKE (1997) verificaram soropositividade em $62 \%, 21 \%$ e $17 \%$ dos animais de raças leiteiras, mestiças e SRD, respectivamente. Em Pernambuco, as raças puras e os mestiços representaram $82,9 \%$ e $17,1 \%$ dos positivos para SRLV. Os animais puros leiteiros agrupados segundo a raça demonstraram frequiência de 43,7\%,30,9\%, 22,4\%, $0 \%$ e $0 \%$ para as raças Parda Alpina, Toggenburg, Saanen, Anglo Nubiana e Mambrina, respectivamente (SARAIVA NETO 1993). No Estado de São

Tabela 3 - Sexo, composição do rebanho, grau de sangue e tipo racial de caprinos negativos e positivos para a artrite encefalite caprina, no Ceará, 1999.

\begin{tabular}{|c|c|c|c|c|c|c|}
\hline \multirow[t]{2}{*}{ Variável } & \multirow[t]{2}{*}{ Estrato } & \multicolumn{2}{|c|}{ Reagente $^{1}$} & \multicolumn{2}{|c|}{ Não reagente ${ }^{1}$} & \multirow[t]{2}{*}{ Tota } \\
\hline & & número & $\%$ & número & $\%$ & \\
\hline \multirow[t]{2}{*}{ Sexo } & Macho & $14^{\mathrm{a}}$ & 2,3 & 606 & 97,7 & 620 \\
\hline & Fêmea & $26^{\mathrm{b}}$ & 0,8 & 3373 & 99,2 & 3399 \\
\hline \multirow[t]{3}{*}{ Categoria } & Reprodutor & $12^{\mathrm{a}}$ & 3,8 & 306 & 96,2 & 318 \\
\hline & Matriz & $25^{\mathrm{b}}$ & 0,9 & 2779 & 99,1 & 2804 \\
\hline & Jovem & $3^{\mathrm{b}}$ & 0,3 & 894 & 99,7 & 897 \\
\hline \multirow[t]{3}{*}{ Grau de sangue } & Raças puras leiteiras & $37^{\mathrm{a}}$ & 4,6 & 773 & 95,4 & 810 \\
\hline & Mestiço & $3^{\mathrm{b}}$ & 0,1 & 2302 & 99,9 & 2305 \\
\hline & Nativo/SRD & $0^{\mathrm{b}}$ & 0,0 & 904 & 100,0 & 904 \\
\hline \multirow[t]{5}{*}{ Tipo Racial } & Pardo Alpina (PA) & $8^{\mathrm{a}}$ & 18,6 & 35 & 81,4 & 43 \\
\hline & Saanen (SA) & $7^{\mathrm{b}}$ & 4,4 & 151 & 95,6 & 158 \\
\hline & Anglo Nubiana & $22^{\mathrm{bc}}$ & 4,0 & 533 & 96,0 & 555 \\
\hline & Mestiço PA x SRD & $1^{\mathrm{bc}}$ & 1,1 & 94 & 99,0 & 95 \\
\hline & Mestiço SA x SRD & $2^{\mathrm{c}}$ & 1,0 & 200 & 99,0 & 202 \\
\hline
\end{tabular}

${ }^{1}$ MIDGA - Microtécnica de imunodifusão em gel de ágar

${ }^{a}$ Letras diferentes na mesma coluna indicam diferença significativa $\left(\chi^{2}\right.$; $\mathrm{p}<5 \%$ ) entre os estratos formados com base no mesmo critério.
Paulo, FERNANDES (1997) verificou freqüências para o CAEV de $89,4 \%$ e $10,6 \%$, para as raças puras e mestiças, respectivamente. Analisando a variável raça, observou-se que o número de animais soropositivos da raça Anglo Nubiana (51\%) foi significativamente maior $(\mathrm{p}<5 \%)$ que os das raças Saanen $25,2 \%$, Alpina $36 \%$ e mestiços $23,5 \%$. NAZARA et al. (1985), SURMAN et al. (1987) e GRANT $\boldsymbol{e t}$ al. (1988) também verificaram maiores prevalências nos rebanhos de raças puras comparados com os mestiços.

Como a principal via de transmissão é via colostro e leite infectados, a fêmea tem papel fundamental na transmissão da infecção. MONICAT (1987) relata que a introdução de fêmeas infectadas com SRLV nos rebanhos acelera a infecção dos mesmos, provavelmente em virtude de fatores, tais como contato íntimo e problemas na ordenha mecânica. Entretanto, a transmissão do lentivírus pelo sêmen deve ser considerada, uma vez que a presença deste no sêmen de machos da espécie caprina, naturalmente infectados foi demonstrada pela técnica de PCR (ANDRIOLI et al. 1999) e em ovinos naturalmente infectados e portadores de orquite brucélica (DE LA CONCHA BERMEJILLO et al., 1996). ROWE $\boldsymbol{e t}$ al. (1993) observaram maiores taxas de soroconversão em fêmeas cruzadas com machos soropositivos do que naquelas cobertas com machos negativos.

Analisando o tipo racial dos reprodutores, verificou-se que as raças Parda Alpina, Anglo Nubiana e Saanen apresentaram, respectivamente, $33,3 \%, 25 \%$ e $5,9 \%$ de animais soropositivos, enquanto as outras raças não apresentaram animais positivos. Esse fato, aliado a um maior número de reprodutores da raça $\mathrm{An}$ glo Nubiana $(54,5 \%$ dos reprodutores positivos), que é a preferida pelos criadores e técnicos no melhoramento de rebanho nativo/SRD, devido a sua adaptação e dupla aptidão, tendem a aumentar a disseminação dessa infecção nos caprinos no Ceará.

Com base nos resultados, pode-se verificar que o CAEV já se encontra disseminado nas várias regiões do Ceará. A aquisição ou troca de reprodutores, com o objetivo de melhoria dos plantéis caprinos, são práticas rotineiras utilizadas pela maioria dos criadores e que facilitam a disseminação do lentivírus, principalmente quando não são utilizadas medidas de prevenção. Por outro lado, a evidência sorológica da presença de SRLV em reprodutores caprinos, associada à recente detecção do vírus no sêmen de caprinos infectados, permitem inferir que a dispersão do agente entre plantéis através da introdução de reprodutores soropositivos ou de sêmen congelado deve ser considerada quando 
do estabelecimento de programas de controle da CAE em caprinos.

\section{AGRADECIMENTOS}

Esta pesquisa foi financiada pela EMBRAPA - Caprinos e pelo Banco do Nordeste e contou com o apoio da Empresa de Assistência Técnica e Extensão Rural do Ceará, Secretaria de Desenvolvimento Rural do Estado do Ceará, Escola de Veterinária - UFMG e do Clube do Berro.

\section{FONTES DE AQUISIÇÃO}

a- Caprine Arthritis-Encephalitis/Ovine Progressive Pneumonia Antibody Test Kit. Veterinary Diagnostic Technology, Inc ${ }^{\circledR}$.

\section{REFERÊNCIAS BIBLIOGRÁFICAS}

ANDRIOLI, A., GOUVEIA, A.M.G., PINHEIRO, R.R., $\boldsymbol{e} \boldsymbol{t} \boldsymbol{a l}$. Detecção do DNA pró-viral do lentivírus caprino em sêmen de bodes naturalmente infectados. Revista Brasileira de Reprodução Animal, Belo Horizonte, v.23, n.3, p.420-421, 1999.

ASSIS, A.P.M.V. Evidência sorológica da ocorrência de lentivírus (Maedi Visna / Artrite Encefalite Caprina) em rebanhos nos Estados de Minas Gerais, Rio de Janeiro, Bahia e Ceará de 1991 a 1993. Belo Horizonte - MG, 1994. 61p. Dissertação (Mestrado em Medicina Veterinária) - Escola de Medicina Veterinária, Universidade Federal de Minas Gerias, 1993.

ASTUDILlO, V.M. Encuestas por muestro para estudios epidemiologicos en populaciones animales. Rio de Janeiro: Organización Panamericana de la Salud - Centro Panamericano de Fiebre Aftosa , 1979. 60p

CRAWFORD, T.B., ADAMS, D.S. Caprine arthritis-encephalitis: clinical features and presence of antibody in selected goat populations. Journal of the American Veterinary Medical Association, n.178, v.7, p.713-719, 1981.

CUNHA, R.G., NASCIMENTO, M.D. Ocorrência de anticorpos para o vírus da AEC em soros de caprinos do Estado do Rio de Janeiro. Revista Brasileira de Medicina Veterinária, Rio de Janeiro, v.17, n.2, p.72-75, 1995.

CUTLIP, R.C., LEHMKUHL, H.D., SACKS, J.M., $\boldsymbol{e} \boldsymbol{t} \boldsymbol{a l}$. Prevalence of antibody to caprine arthritis-encephalitis virus in goats in the United States. J ournal of the American Veterinary Medical Association. v.200, n.6, p.802-805, 1992.

DAWSON, M. The caprine arthritis encephalitis syndrome. Veterinary Annual, v.29, p.98-102, 1989.

DAWSON, M., WILESMITH, J.M. Serological survey of lentivirus (maedi-visna/ caprine arthritis encephalitis) infection in British goat herds. Veterinary Record, v.117, n.4, p.86-9, 1985.

De La CONCHA-BERMEJILLO, A., MAGNUS-CORRAL, S. BRODIE, S.J., et al. Veneral shedding of ovine lentivirus in infected rams. American Journal of Veterinary Research, v.57, p.684-688, 1996.

DEAN, A.G., DEAN, J.A., BURTON, A.H., et al. Epi info, version 6: a word processing, database and statistic program for epidemiology on micro-computers. Atlanta, Georgia : Center for Disease Control, 1992. 302p.

FERNANDES, M.A. Artrite Encefalite Caprina: Contribui- ção para o estudo epidemiológico em rebanhos leiteiros criados no Estado de São Paulo. São Paulo - SP, 1997. 83p. Dissertação (Mestrado- Clínica Veterinária) - Faculdade de Medicina Veterinária e Zootecnia da Universidade de São Paulo, 1997.

GOUVEIA, A.M. Padronização de microtécnica de imunodifusão em gel de agarose para diagnóstico de lentivírus Pneumonia Progressiva Ovina (OPP) - Maedi-Visna (MVV) - Artrite Encefalite Caprina (CAEV). Sobral, 1994. 4p. (mimeografado).

GRANT, G.H., JOHNACHAN, P.M., OLIVEIRA, D., et al. Seroprevalence of Caprine Arthritis-encephalitis in jamaican goat population. Tropical Animal Health and Production, v. 2 0, p.181-182, 1988.

IBGE. Censo Agropecuário 1995-1996. Rio de Janeiro, 24 abr. 1999. Especiais. Capturado em 24 abr. 1999. On line. Disponível na internet: http://www.sidra.ibge.gov.br/.

MCGUIRE, T. C. The imune response to viral antigens as a determinant of arthritis in Caprine Arthritis-Encephalitis infection. Veterinary Immunology and Immunopathology, v. 17, n. 1, p. $465-470,1987$

MELO, A.C.M., FRANKE, C.R. Soroprevalência da infecção pelo vírus da Artrite-Encefalite Caprina (CAEV) no rebanho de caprinos leiteiros da região da grande Fortaleza, Ceará, Brasil. Ciência Rural, Santa Maria, v.27, n.1, p.113-117, 1997.

MONICAT, F. Facteurs de risque des arthrites des caprins. In: LES RENDEZ-VOUS DE LECOPATHOLOGIE, 1987, Lyon, France. Premiers resultats... Rhone-Alpes: Villeurbanne, Center Regional de L'Ecopathologie Multespeces, 1987. p.1-28

MOOJEN, V., SOARES, H.C., RAVAZZOLO, A.P., $\boldsymbol{e} \boldsymbol{t} \boldsymbol{a l}$ Serological evidence of lentivirus (maedi-visnalcaprine arthritis encephalitis) in goats in Rio Grande do Sul - Brazil. Arquivos da Faculdade de Veterinária, Porto Alegre, v.14, p.77-78, 1986

NAZARA, S.J., TRIGO, F.J., SUBERBIE, E., et al. Estudio serologico de la artritis-encefalitis caprina en México. Tecnica Pecuaria en México. v.48, p.98-101, 1985.

PINHEIRO, R.R., EGITO, A.S., SANTA ROSA, J., $\boldsymbol{e} t \boldsymbol{a l}$ Artrite encefalite caprina viral (CAEV). Sobral, CE : EMBRAPA-CNPC, 1989. 5p. (EMBRAPA-CNPC. Comunicado Técnico, 19).

ROWE, J.D., EAST, N.E., THURMOND, M.C. Cohort study of natural transmission and two methods for control of caprine arthritis-encephalitis virus infection in goats. American Journal of Veterinary Research, v.54, p.1858-1862, 1993.

SARAIVA NETO, A.O. Soroprevalência da Artrite Encefalite Caprina em plantéis caprinos leiteiros no Estado de Pernambuco. Recife - PE, 1993. 70p. Dissertação (Mestrado em medicina Veterinária Preventiva) - Faculdade de Medicina Veterinária, Universidade Federal Rural de Pernambuco, 1993.

SILVA, R.R. Sistema agroindustrial da caprinocultura leiteira no Brasil. Campina Grande - PB, 1996. 38p. Monografia - Curso de Especialização em Agribusiness, Universidade Federal da Paraíba, 1996.

SURMAN, P.G., DANIELS, E., DIXON, B.R. Caprine arthritisencephalitis virus infection of goats in South Australia. Australian Veterinary Journal, v.64, p.266-271, 1987. 